\title{
ROTINAS BUROCRÁTICAS E LINGUAGENS DO ESTADO: \\ POLÍTICAS DE REGISTROS ESTATÍSTICOS CRIMINAIS SOBRE MORTES VIOLENTAS NO RIO DE JANEIRO E EM BUENOS AIRES
}

Ana Paula Mendes de Miranda

\author{
María Victoria Pita
}

\begin{abstract}
RESUMO
Este artigo parte do interesse em produzir uma base de dados comparável das regiões metropolitanas do Rio de Janeiro e de Buenos Aires. Ao longo da pesquisa verificou-se que para atingir tal objetivo seria necessária a explicitação dos processos técnicos e das competências politicas que, no Brasil e na Argentina, deram lugar a modos específicos de produção de informação em matéria de criminalidade, com destaque às conjunturas particulares que levaram, em cada caso, a que os dados oficiais sobre criminalidade fossem objeto de disputas políticas, e à existência de conflitos intra e interinstitucionais. O que era, também, matéria de que se nutria a "opinião pública" quando o debate sobre a segurança pública ascendia no ranking da agenda pública. Tal abordagem permite concluir que as cifras falam mais sobre as instituições que a produziram do que sobre a criminalidade ou sobre a situação das mortes violentas nas regiões metropolitanas do Rio de Janeiro e de Buenos Aires. Portanto, neste artigo, tratar-se-á de apresentar como esses dados, para poderem ser considerados comparáveis entre regiões metropolitanas tão próximas e tão distantes como Buenos Aires e Rio de Janeiro, necessitaram ser (de)compostos e (des)agregados para poder-se compará-los e lê-los como indicadores de formas violentas de resolução de conflitos.
\end{abstract}

PALAVRAS-CHAVE: registros; criminalidade; mortes violentas; comparação.

\section{INTRODUÇÃO}

O que cifram as cifras? Sobre que acontecimentos, quais processos, enfim, sobre quais dados nos falam os números? Quais rotinas burocráticas cristalizadas possibilitam que certos fatos sejam convertidos em registros, o que, por sua vez, representam uma medida, um indicador, uma forma de retratar a "realidade" de forma pretensamente objetiva e padronizada, mas que conforme lido e interpretado pode-se revelar um número valioso de disputas políticas corporativas (policial e judicial) e midiáticas no processo de formulação de políticas públicas?

Essa abordagem é sobre os dados quantitativos referentes à criminalidade 1 , qua constructo,

\begin{tabular}{l}
\hline Julga-se que o uso da categoria "criminalidade" é mais \\
adequado do que a de "crime", pois a primeira enfatiza tanto \\
os vínculos societários entre os indivíduos quanto as práti- \\
cas institucionais, enquanto o "crime" restringe-se à dimen- \\
são legal (KANT DE LIMA, MISSE \& MIRANDA, 2000).
\end{tabular} isto é, pensados como resultado de uma série de processos e rotinas específicas de produção de informação. Parte de uma evidência etnográfica de que as estatísticas nem mentem, nem dizem a verdade. Tal perspectiva permite que se levante todas essas perguntas, mesmo correndo o risco de não poder respondê-las e mesmo assim continuar mantendo-as como guias orientadoras, como parte de nossa caixa de ferramentas para pensar as cifras oficiais referidas aos delitos registrados. Isso significa afirmar que não estamos tratando de "estatísticas", mas sim de processos de construção de registros de informações que, ao serem quantificadas, passam a representar oficialmente diferentes tipos de fenômenos e consolidam-se como argumentos políticos na esfera pública.

Este artigo possui vários objetivos que resumem os primeiros resultados da pesquisa "Análisis comparado de políticas de producción de registros estadísticos criminales en Río de Janeiro y 
Buenos Aires", que nós, pesquisadores brasileiros e $\operatorname{argentinos}{ }^{2}$, iniciamos há um tempo. É justo dizer que parte desses resultados é uma série de dados sobre mortes violentas nas regiões metropolitanas do Rio de Janeiro e de Buenos Aires, referente aos anos 2002 a 2005, que se encontra ao final deste trabalho.

No entanto, como todos os participantes deste projeto foram em algum momento, ou ainda são funcionários em organismos públicos produtores de informações sobre criminalidade, é preciso destacar que somos, portanto, conhecedores, em maior ou menor medida, dos processos de produção destes dados, das diversas lógicas institucionais que orientam sua produção e que ocasionalmente se articulam e/ou colidem, bem como as diversas leituras sobre estes dados. Nesse sentido, entendemos que era necessário, simultaneamente ao processo de produção de dados consistentes e comparáveis, descrever e explicar como são produzidos estes dados, o que envolve o desenvolvimento das etapas de construção destes dados para conhecer o alcance, e também, as limitações dos mesmos, o que nos levou a iniciar una espécie de etnografia da produção de estatísticas oficiais em matéria de criminalidade (progressos parciais podem ser vistos em Miranda e Dirk (2010), Pita e Olaeta (2010) e Miranda e Pita (no prelo)), o que é descrito como um dos resultados da pesquisa.

Algum tempo depois de iniciado este projeto de pesquisa ficou claro que aquilo que se formulou como ponto de partida e suposição central tornou-se uma evidência e condição necessária: seria impossível aos pesquisadores do projeto expor e analisar dados sem considerar os modos pelos quais esses têm sido produzidos, e isso porque o modo como foram gerados dá conta de seu significado e alcance. Desse modo, para possibilitar a geração de uma base de dados comparável, em primeiro lugar deve-se, conjuntamente, expli-

2 O subprojeto "Análise Comparada de Políticas de Produção de Registros Estatísticos Criminais no Rio de Janeiro e em Buenos Aires", integrou o projeto PRONEX FAPERJ/CNPq, Sistemas de Justiça Criminal e Segurança Pública em uma Perspectiva Comparada: Administração de Conflitos e Construção de Verdades, coordenado pelo Professor Titular Roberto Kant de Lima (2007-2009). A equipe de trabalho foi composta pelas autoras e por Hernán Olaeta e Renato Coelho Dirk. car os processos técnicos e as competências políticas que, em cada país, davam lugar a um circuito particular de informação em matéria de criminalidade. Também se deve referir sobre as conjunturas particulares que levaram, em cada caso, a que os dados oficiais sobre criminalidade fossem objeto de disputas políticas, da existência de conflitos intra e inter-institucionais, e também, da matéria de que se nutria a "opinião pública" quando o debate sobre a segurança pública ascendia no ranking da agenda pública. Pôr em jogo essas semelhanças e diferenças nos processos técnicos e as competências políticas no momento de construir uma base de dados, em termos práticos, implicou tomar uma importante quantidade de decisões, o que permite afirmar que as cifras falam mais sobre as instituições que a produziram do que sobre a criminalidade ou sobre a situação das mortes violentas nas regiões metropolitanas do Rio de Janeiro e de Buenos Aires.

Em outros trabalhos (MIRANDA \& DIRK, 2010; PITA \& OLAETA, 2010; MIRANDA \& PITA, no prelo) volta-se a atenção à descrição e análise de "quem produz o quê", ou melhor, ocupa-se especificamente de explicar quais agências e por meio de que rotinas burocrático-administrativas são produzidos os dados nos dois países Argentina e Brasil. Também se analisam os problemas encontrados nos dois organismos públicos encarregados de produzir as estatísticas oficiais sobre criminalidade, destacando como a sua produção necessariamente colocava em confronto a linguagem do direito e a linguagem policial, assim como lógicas políticas diversas, aquela que procura fazer a gestão de dados para produzir informação oficial e pública e aquela que pretende que o tratamento dos dados, chamado de "análise criminal", esteja voltado para a resolução de um fato delituoso. Ainda nestes trabalhos procura-se demonstrar como mais de uma vez a lógica que orienta o debate público em torno da segurança dá lugar a um uso (por parte de funcionários públicos como os agentes dos meios de comunicação) dos dados para fundamentar ou argumentar posições que, inevitavelmente, contornam a complexidade dessa construção e, portanto, das limitações, dos dados existentes. Assim, foi possível concluir que os dados sobre criminalidade, sobre os quais há sempre uma suposição de intencionalidade perversa ou de ignorância, são tratados como verdade irrefutável nas argumentações, o que não somente propicia que sejam 
desenvolvidos debates que levariam à formulação de políticas públicas, como revelam um uso fetichista da informação quantitativa. Foram inúmeros debates travados publicamente em torno da verdade ou mentira dos dados, segundo o qual os números consideravam-se favoráveis ou contrários ao que se desejava argumentar, deixando claro que as disputas não se restringiam ao plano político-partidário, mas também a disputas interinstitucionais entre as agências responsáveis pela segurança pública, chegando a envolver também disputas entre grupos acadêmicos que realizam pesquisas na área

Neste artigo, busca-se expor outro capítulo de nosso projeto de pesquisa, que se destina a descrever o processo de trabalho que levamos adiante para produzir uma série de dados, que será apresentada ao final do artigo. Descrever-se-á um processo de trabalho, que se pretende técnico, mas que conforme avança a descrição vai ficando cada vez mais evidente que não é possível considerar que os processos técnicos, como metodologias exportáveis e importáveis, sejam desvinculados de tradições burocrático-administrativas setoriais e locais, no que se inclui o enorme corpus jurídico, que transforma os fatos em objetos judicializáveis. Ficou claro, em nosso ponto de vista, que os dados resultam de decisões administrativas, de modalidades particulares de tratar fatos codificados como delitos, e também, de tradições institucionais que expressam ideologias próprias, ou seja, um saber fazer e um modo particular de fazer as coisas. Assim, os fatos que são classificados como violentos, e que envolvem a pratica de um crime, ao serem capturados pelo sistema penal acabam sendo processados de um modo determinado, que por sua vez supõe uma série de microdecisões e procedimentos. Assim, ao analisar um dado é preciso lembrar que ele nos fala de diferentes perspectivas, além de informar algum conflito, refere-se também a uma prática, um sistema classificatório, a vários atores. Portanto, o dado construído informará algo que se constituirá no que sabemos que acontece. Neste artigo, então, tratar-se-á de mostrar como esses dados, para poder ser considerados comparáveis entre regiões metropolitanas tão próximas e tão distantes como Buenos Aires e Rio de Janeiro, necessitam ser (de)compostos e (des)agregados para logo poderem ser comparados e lidos como indicadores de formas violentas de resolução de conflitos.

\section{HOMICÍDIOS OU MORTES VIOLENTAS? EMBUSCADE UMACATEGORIA}

A pesquisa que originou este artigo surgiu de um interesse de contar com dados comparativos, provenientes de fonte policiais, sobre mortes violentas, em particular para os casos denominados como homicídios nas áreas metropolitanas de Buenos Aires e Rio de Janeiro. Considerou-se que trabalhar com dados referentes a mortes violentas, a partir de uma análise quantitativa, possibilitaria uma percepção acerca dos níveis de violência social, entendida como um fenômeno relacional, cuja principal característica em nossas sociedades é a impossibilidade de regulação da ordem pública em consonância com a garantia de direitos civis fundamentais (PERALVA, 2000), já que se considera que os dados de homicídios dão conta, em grande medida, de formas extremas e violentas de administração de conflitos. Outro fator relevante para a escolha foi que há um consenso entre os pesquisadores desta área temática de que os dados referentes aos homicídios são os que apresentam o menor índice de sub-registro. No entanto, é preciso lembrar que o homicídio é uma categoria jurídica que corresponde à ação de matar alguém, o que obrigou também a esclarecer-se o uso da categoria mortes violentas, que foi incorporada, no Rio de Janeiro, tanto pelo sistema de saúde quanto pelo de justiça criminal, e posteriormente pela mídia.

A estratégia de análise foi a leitura dos registros de ocorrências policiais visando à identificação da circunstância da morte para que fosse possível delimitar como eram realizados os procedimentos burocráticos e jurídicos pelos agentes do Estado. Assim, quando ocorria uma morte natural, originada por doenças não relacionadas a acidentes ou agressões, o fato deveria ser registrado apenas pelo sistema de saúde. Já em casos de morte violenta foi necessário classificar os casos em outros tipos, a saber, morte acidental, homicida e suicida. Em todos os casos de morte violen$t a$ no Brasil, para que a morte seja registrada como um óbito ${ }^{3}$ é preciso um laudo do Instituto Médico Legal, vinculado à Polícia Civil, caracterizan-

\footnotetext{
3 No Brasil os documentos que atestam a morte de um indivíduo são a Declaração de óbito, fornecida por um médico apontando as causas da morte, e a Certidão de óbito, que é emitida por um Cartório de Registro Civil, sem o qual não se pode realizar o sepultamento.
} 
do que a causa da morte é externa ${ }^{4}$. Desse modo, a instituição policial não tem acesso a todos os tipos de mortes, mas apenas àquelas relacionadas a possíveis crimes. Por exemplo, em um caso registrado na polícia como tentativa de homicídio, cuja vítima falecer posteriormente em decorrência dos ferimentos sofridos, na maioria das vezes, não será classificado como homicídio, o que afetará a atualização das informações estatísticas ${ }^{5}$. Nos dados provenientes do sistema de saúde (Sistema de Informações de Mortalidade (SIM)) os casos de mortes violentas também não representam todas as mortes ocorridas, mas os problemas de qualidade das informações têm outras explicações, das quais vale ressaltar a dificuldade de identificação dos cadáveres.

O mesmo acontece na Argentina, onde a categoria mortes violentas somente é empregada como categoria de agregação, tanto no sistema de saúde como nas agências que sistematizam informações do sistema penal. No caso do sistema de saúde é usada fundamentalmente para distinguir as mortes resultantes de enfermidades daquelas provocadas por causas naturais, e basicamente dão conta de mortes por acidentes (incluindo os de trânsito), suicídios e homicídios. No caso das agências que sistematizam informações do sistema penal referentes a todos os tipos de mortes tramitados, distinguindo os tipos penais que se referem a cada uma, diferenciando os homicídios dolosos, culposos, culposos por acidentes de trânsito e suicídios ${ }^{6}$.

\footnotetext{
4 O termo “causas externas" é utilizado pela área de saúde, no Brasil, para referir-se à mortes por homicídios, suicídios, agressões físicas e psicológicas; acidentes de trânsito, transporte, quedas, afogamentos e outros; lesões e traumas provocados também por esses eventos (MINAYO, 2009).

5 Sobre uma comparação dos dados da saúde e da polícia, ver Dirk (2007).

6 Os dados sobre suicídios analisados pela Dirección Nacional de Política Criminal, vinculada ao Ministério de Justicia y Derechos Humanos, informam que se o suicídio é uma conduta que atenta contra a própria vida, não caracteriza um delito e não há punição, a exceção é apenas quando alguém "[...] instiga a outro ao suicídio ou ajuda a cometêlo, se o suicídio tenha sido tentado ou consumado" (BRASIL, 1940, art. 83). De fato, o suicídio ou as condutas suicidas são consideradas geralmente questões de saúde pública e não de caráter penal. Porém, os suicídios constituem um dos tipos de morte por causas "não-naturais", sendo portanto parte do campo de interesse e preocupação ao momento de comparar estes dados com outros tipos de
}

Na verdade, a adoção da categoria morte violenta foi uma decisão tomada durante o próprio trabalho de pesquisa. E fez-se não só buscando certa tradutibilidade entre as instituições do sistema de justiça penal e outras instituições estatais e os mass media, porque consideramos necessário distinguir esses fatos das categorias penais, que os colocavam em tipos diferentes, o que implica em tratamentos judiciais diferenciados e valorações morais distintas, o que em algumas ocasiões deixavam fora da contabilização oficial como mortes. Adiante, voltar-se-á a essa questão.

Os tipos de morte que foram analisados tiveram como critérios de seleção a possibilidade de contar com dados consistentes, e fundamentalmente, comparáveis. Para isso, detemo-nos na análise do processo de trabalho de elaboração desses dados - do Instituto de Segurança Pública (ISP) ${ }^{7}$, para o caso do Rio de Janeiro, e da Dirección Nacional de Política Criminal (de agora em diante DNPC $)^{8}$, para o caso da área metropolitana de Buenos Aires, para conhecer assim o alcance e as limitações dos mesmos, mas também buscar dar conta do processo de produção da informação.

\section{OS FATOS CONVERTEM-SE EM REGIS- TROS}

A que eventos referem-se os dados? Como se articulam, de maneira mais ou menos conflituosa, os diversos saberes técnicos e políticos que operam ou intervêm sobre eles? O registro dos fatos nos contextos analisados supõe o uso de uma técnica que transforma a história contada pelas vítimas ou os supostos delinqüentes em um relato impessoal utilizando-se de procedimentos burocráticos e jurídicos. Também é sabido que essa forma de narração difere-se da linguagem científica, que se caracteriza por estabelecer uma rela-

mortes por causas não naturais, tal como os homicídios dolosos e culposos (destacando-se dentre os últimos aqueles ocorridos em acidentes de trânsito).

7 Trata-se de uma autarquia estadual, vinculado à Secretaria de Estado de Segurança, que foi criada em dezembro de 1999, para assegurar, gerenciar e executar a política de segurança do Estado do Rio de Janeiro, elaborando o planejamento da força policial que mais atenda às necessidades da sociedade.

8 Organismo nacional vinculado ao Ministerio de Justicia, que é o encarregado de processar, sistematizar e publicar aqueles que se constituirão em dados oficiais. 
ção entre a "realidade" e sua representação na busca de algo universal, em especial, a identificação de padrões. Outro aspecto importante é que o sistema penal caracteriza-se por manter sua tradição inquisitiva de busca da verdade por meio, principalmente, da suspeição, por isso toda documentação juntada aponta à imputação de um crime a um sujeito considerado suspeito 9 . No caso dos registros policiais, os processos de trabalho dãose de forma particular. $\mathrm{O}$ registro representa o começo do trabalho de classificar os conflitos, de modo que os agentes chegam à conclusão de que "cada caso é um caso"10. Portanto, ao processar a informação, os registros policiais acabam descontextualizando os fatos, desconsiderando que o "conteúdo" a que se referem é resultado de diversas práticas inter e intra-institucionais, que convergem e também colidem em função de diferentes lógicas forjadas em processos de trabalho e definições de categorias sobre os fatos.

$\mathrm{Na}$ Argentina existe uma ampla gama de delitos que, ao não serem denunciados por suas vítimas, nem "pegos" pela polícia, não ingressam ao circuito judicial e, portanto, não são registrados na estatística oficial, fenômeno que é conhecido comumente como "cifra negra". Conforme estudos de vitimização desenvolvidos na Cidade de Buenos Aires e no Conurbano, aproximadamente $70 \%$ das vítimas de roubos e furtos não o relataram (Informe Encuesta de Victimización CABA, 2006, DNPC $)^{11}$. Trata-se principalmente de grande parte de roubos, furtos, lesões e crimes sexuais, que por diferentes razões não são informados: porque a vítima não quer perder tempo, porque não crê que se pode esclarecer o fato, porque não confia no sistema de justiça etc. Também há

9 Era comum no ISP o recebimento de solicitações de informações sobre crimes encaminhados pelo Ministério Público ou pela Defensoria Pública para anexar em processos judiciais. Mais raramente os pedidos eram feitos por particulares para este objetivo.

10 É comum no meio policial ouvir que "cada caso é um caso", o que impossibilitaria a construção de estratégias de análise a partir da definição de padrões dos crimes e criaria uma dificuldade maior para pensar-se a investigação dos homicídios (MIRANDA, OLIVEIRA \& PAES, 2010).

11 Estudos de vitimização realizados na área metropolitana de Rio de Janeiro (2006-2007) indicaram que 35,50\% das vítimas de roubos e furtos denunciaram-nos (MISSE, 2008). uma elevada quantidade de delitos que não se baseiam em denúncias de particulares e que são muito difíceis de serem captados pelo sistema de justiça por deficiências próprias dos organismos de controle: como o caso dos denominados "delitos complexos", narcotráfico, lavagem de dinheiro etc.

Outra importante observação refere-se à seletividade do sistema de justiça na recepção dos crimes. Basta analisar qualquer estatística oficial (registros policiais, ações penais ou pessoas punidas com privação de liberdade) para observar que o perfil dos imputados pelo cometimento de um crime responde a um padrão determinado. Em primeiro lugar, há que se levar em conta que cerca de $70 \%$ dos fatos delituosos registrados são delitos contra a propriedade (basicamente roubos e furtos), dos $30 \%$ restantes destacam-se as lesões (dolosas e culposas) e as infrações à lei de drogas. Essa característica tem a ver com o tipo de infração que habitualmente denuncia-se (basicamente roubos pessoais, de veículos e de residências) e com os crimes que se iniciam pela própria atuação da polícia nas denominadas tarefas de prevenção, o que aponta principalmente ao modo como as polícias lidam com os "crimes de rua" cometidos por um infrator que reúne os elementos considerados a priori como de "periculosidade". Por isso não é de surpreenderse que entre os delitos sobressaiam-se os roubos de rua $\mathrm{e}$ as infrações relacionadas às drogas ilícitas. Se muitas dessas limitações não se aplicam ao caso do homicídio doloso, por tratar-se de um delito com um alto nível de registro oficial, é preciso lembrar que se trata de um dado surgido de uma fonte particular, de acordo com categorias e interpretações específicas da agência produtora da informação, que devem ser "traduzidas" em uma lógica jurídica, o que orienta o formulário com as informações para a confecção de estatísticas oficiais.

Essa questão possui especial importância, já que toda vez que se elabora estatísticas pela Dirección Nacional de Política Criminal requere-se à polícia que se classifique um fato de morte com a categoria jurídica homicídio doloso, que a rigor somente será validada ao final de um processo judicial. Dá-se, então, nesse momento total liberdade de ação - e sem nenhum tipo de procedimento de controle ou padronização, que provê o próprio exercício do oficio no qual o policial toma a decisão, a partir do saber empírico, de agir ou não, e de como intervirá no caso. Portan- 
to, os policiais que chegam ao lugar do fato ou que participam do fato que resulta em uma morte reconstroem o acontecimento a partir de relatos, declarações e de sua presença no local, construindo assim o material que constituirá parte das primeiras atuações policiais, integrando o expediente judicial: as ações policiais que formarão parte da instrucción da causa ou do expediente judicial, isto é, aquilo que a polícia produzir em seu caráter de auxiliar da justiça. Porém, ainda que os policiais considerem que se trata de um homicídio doloso, a rigor essa é uma categorização judicial, somente ao final do processo judicial poderá ser afirmado. O resultado é o registro do fato que se compilará e sistematizará para construir as estatísticas policiais, com base nas quais completarse-ão as planilhas que enquadrarão o fato como um tipo de caso particular (a categoria homicídio doloso), para informar ao DNPC. A polícia está interpretando o fato e possivelmente atribuindo intencionalidade ao ato de matar somente movido pela obrigação burocrática de completar a informação requerida pela DNPC.

$\mathrm{Na}$ tradição jurídica brasileira, o registro em cartório é necessário para dar publicidade, autenticidade, segurança e eficácia aos atos praticados, assegurando o cumprimento das formalidades legais necessárias a cada situação. A "lógica cartorial" permeia os procedimentos jurídico-burocráticos, o que implica que o registro é algo que deve ser feito pelo Estado para o próprio Estado, com o objetivo de criar uma interpretação autorizada sobre os fatos. É preciso destacar que a legitimidade do registro está dada pela "fé pública"12, quer dizer, pela imposição de certeza-veracidade ao documento produzido, que é dada pelo cartório (MIRANDA, 2000). Portanto, é possível compreender por que o registro de ocorrência não reproduz literalmente o discurso do "depoente", seja vítima, agressor ou testemunha, e, sim, reinterpreta-o em termos burocráticos e jurídicos. Tudo o que é dito é repetido pelo delegado ao oficial de cartório, de modo a traduzir os fatos acontecidos em narrativas de segunda mão, nas quais predomina a linguagem jurídica. Assim, pode-se afirmar que o registro policial é um ato 12 Embora a "fé pública" não assegure o conteúdo do
documento, funciona como atestação de veracidade. Deve-
se lembrar que, no Brasil, os documentos públicos possu-
em valor de "prova plena". interpretativo do Estado por meio da polícia, constituindo-se em uma primeira representação do fato delituoso pela instituição policial. Trata-se de um documento provisório, pois é elaborado com base nas primeiras informações que a polícia incorpora acerca do fato, que é posteriormente entranhado ao processo judicial (KANT DE LIMA, 1995). As informações que constam no registro de ocorrência vão orientar a investigação subseqüente $\mathrm{e}$ serão complementadas, confirmadas ou refutadas no decorrer da investigação. A investigação policial tem por base o inquérito policial que é iniciado, nos casos de ação penal pública, de ofício, mediante requisição da autoridade judiciária ou do Ministério Público, ou mediante requerimento do ofendido ou de quem tiver qualidade para representá-lo ${ }^{13}$. Considerando que o registro é um ato interpretativo do Estado sobre os fatos e que o oficial de cartório possui fé pública, a estatística oficial não tem relação com tudo o que acontece, mas sim com aquilo que a instituição policial decide registrar e, conseqüentemente, atestar sua veracidade. Nesse sentido, a discussão política sobre a verdade ou mentira sobre as estatísticas oficiais torna-se problemática, pois a informação que se publica no Diário Oficial, pelo Instituto de Segurança Pública, possui um estatuto de "verdade oficial", conferida automaticamente pela autoridade legítima do Estado, independente da veracidade de seu conteúdo.

Assim, quando alguém fala que "as estatísticas mentem", o debate político direciona a discussão com base na crença de que as cifras deveriam reproduzir fielmente a realidade, sendo que a prática revela que elas são construções feitas a partir de uma determinada perspectiva, a visão policial sobre os crimes. Nesse caso, seria mais adequada uma reflexão sobre a seletividade policial, que julga os fatos com base em critérios pessoais e institucionais, o que é mais "grave", de modo que os conflitos interpessoais sejam desconsiderados e desqualificados como questões de menor relevância.

No caso de Argentina, em Buenos Aires, diferentemente do Brasil, especificamente do Rio de

13 O artigo $5^{\circ}$, incisos I e II, do Código de Processo Penal Brasileiro, descreve quando o Inquérito Policial é iniciado nos casos de ação penal pública, isso é, quando o titular da ação penal é o Estado em função da natureza do bem jurídico violado, o que se aplica ao caso do homicídio doloso. 
Janeiro, a polícia produz um tipo de informação para o poder judicial e outro para a DNPC, sendo o primeiro um relato dos fatos que constituirá parte do que se chama a instrução policial e que inicia o expediente judicial, e o segundo corresponde a um registro quantitativo que se informa em planilhas produzidas pela própria DNPC. Porém, esses dados, ainda que não sejam publicados em um Boletim Oficial, também possuem caráter de dados oficiais. Por isso, do mesmo modo, o importante é dar conta do momento do processo de trabalho policial e das lógicas que intervêm ao registrar-se ou não um fato e como se faz.

\section{TORNANDO POSSÍVEL A COMPARAÇÃO}

O foco da comparação na perspectiva antropológica é a busca da diversidade, e não da semelhança (BARTH, 2000), o que significa dizer que a comparação etnográfica não se refere ao próprio objeto descrito, mas contrasta as descrições. Dito de outro modo, ao serem analisados os registros procurou-se pistas que permitiam entender os significados que eles possuíam em cada contexto e lugar, para posteriormente perceber como eram interpretados por aqueles que o "produziam". As variações de significado sobre os registros de mortes violentas foram levando à construção de hipóteses explicativas sobre os processos subjacentes a sua produção. Nesse sentido, identificamos que para compreender as diferenças em relação aos conhecimentos empregados na definição do que seriam as mortes violentas, em especial, os casos de homicídio, era preciso ficar atento aos seguintes parâmetros:

1. O período temporal: definir o período a considerar, levando-se em consideração que o objetivo era uma extensão temporal significativa, mas ao mesmo tempo não escolher anos, cujos dados sabia-se que tiveram problemas técnicos que afetavam sua qualidade, foi uma decisão importante. Por exemplo, o ano 2000 foi na Argentina, o primeiro ano da implantação a nível nacional do Sistema Nacional de Información Criminal, que delegou a DNPC a função de confeccionar a estatística anual sobre criminalidade e funcionamento do sistema de justiça penal do país, sobre a base da informação registrada pelas polícias, forças de segurança (prefeitura naval argentina, com poder de polícia nas zonas portuárias, rios e mar; gendarmeria, com poder de polícia nas zonas fronteiriças), e pelos tribunais, pelo ministério público na área penal e os serviços penitenciários, respectivamente ${ }^{14}$. Para os objetivos deste artigo trabalhou-se exclusivamente com a informação produzida pelas polícias, a prefeitura naval e a gendarmeria. Como esse ano foi o primeiro na implantação do sistema, não se encontrava suficientemente consolidado e contava com importantes carências de informação. Isso sugere que, por exemplo, em uma categoria particular de delitos não se tenha certeza se um zero implica ausência de ocorrência de casos ou ausência de registro de informação sobre casos acontecidos. Por isso, a decisão foi iniciar-se a série com o ano 2001, período para o qual a DNPC já havia realizado capacitações e gerado um sistema de controles das informações recebidas (ainda assim, no caso dos dados referidos a vítimas e autores somente conta-se com informação completa a partir do mês de julho desse ano). No caso do Rio de Janeiro ${ }^{15}$, os dados passaram a ser publicados mensalmente no Diário Oficial ${ }^{16}$ a partir do ano de 1999, como parte do Programa de Qualificação Estatística e Relação com a Mídia, o que passou a dar maior confiabilidade aos dados produzidos pela Polícia Civil. Em 2000, foi criado o Núcleo

14 O sistema foi criado e implantado em virtude da Lei n. 25266 , que modificou a Lei n. 22 117. Existe um projeto de regulamentação desta norma que, entre outras questões, especifica como se programarão os sistemas de informação sobre criminalidade: periodicidade no envio da informação, organismos obrigados a informar, apresentação de informes, publicações, controle da informação remetida, intimação para sua retificação ou ratificação etc., que ainda não está vigente.

15 No caso do Brasil, apenas em 2003 foi desenvolvido o Sistema Nacional de Estatísticas de Segurança Pública e Justiça Criminal (Sinespjc), com o objetivo de reunir as informações de segurança pública e justiça criminal produzidos pelos estados, que até hoje apresenta problemas de cobertura em função das características regionais. O Rio de Janeiro é um dos poucos estados cujos dados possuem $100 \%$ de cobertura, mas não há pesquisas que avaliem a qualidade dessas informações.

16 Trata-se de um veiculo de comunicação oficial, cuja criação remonta a chegada de D. João VI ao Brasil, voltado a imprimir com exclusividade os atos normativos e administrativos nos âmbitos do governo federal (Decreto n. 4 520 , de 16 de dezembro de 2002), estadual e municipal. 
de Pesquisa em Justiça Criminal e Segurança Pública (Nupesp), vinculado ao Instituto de Segurança Pública, tendo como finalidades principais produzir os relatórios estatísticos sobre o sistema de segurança pública estadual. Inicialmente, só foi possível trabalhar-se com os dados agregados, mas após o ano de 2002 o Nupesp passou a ter acesso com regularidade aos micro-dados ${ }^{17}$ da Polícia Civil, o que possibilitou o desenvolvimento e coordenação de análises que contribuíram para o aprimoramento da qualidade das informações policiais, em especial, no que se refere à desagregação por Áreas Integradas de Segurança Pública (AISP) ${ }^{18}$, a fim de produzir mapas de risco com indicação de pontos de concentração de ocorrências de crimes, entre outras análises. Participaram desse projeto diversos setores da sociedade, em especial, pesquisadores que estudam a temática da violência, criminalidade e segurança pública (MIRANDA, 2008). Nos dois casos ficou claro que se podia tomar a decisão do recorte temporal a partir de 2002 por ter-se participado de alguma forma de seu processo de produção.

2. O alcance territorial: definir a área a considerar também foi uma questão que supôs uma importante série de "micro-decisões" e explicitações. Estima-se que fosse especialmente valioso poder contar com informações das cidades e da área metropolitana que as circundam. Assim, estariam sendo consideradas áreas relativamente semelhantes no que se refere a seu caráter urbano e também em termos de população. Mas isso teve implicações no caso da Argentina, já que os dados referentes à "região metropolitana" referem-se a distritos independentes, que

17 O microdado é a menor parte observável de uma base de dados; é o conjunto, em meio digital, de todas as informações que compõe uma base de dados (BORGES \& DIRK, 2006).

18 Trata-se da correspondência geográfica entre a área de um batalhão da Polícia Militar (responsável pelo policiamento ostensivo e a preservação da ordem pública) e uma ou mais circunscrições de delegacias da Polícia Civil (exercendo as funções de polícia judiciária e apuração de infrações penais). eram fornecidos pela DNPC separadamente e considerar também que se referiam a duas polícias diferentes (a polícia federal e a da província de Buenos Aires), com tradições de trabalho diferentes, com rotinas de trabalho distintas e, portanto, também com "desvios" e "erros" diversos.

3. As categorias nativas: definir com precisão as categorias de uma e da outra base de dados que seriam consideradas para construir a categoria de mortes violentas foi resultado de importantes discussões atendendo ao que em cada país e, especificamente, em cada agência produtora de informação, registrava-se. É possível dizer que isso implicou construir um "tradutor" de categorias de um e outro país, o que por sua vez implicou em desconstruir o próprio, e particular, processo de registro e interpretação dos fatos por parte de cada uma das agências intervenientes.

Assim, foi como considerar-se que para o caso do Rio de Janeiro deviam ser incluídas as categorias de homicídio doloso, mas também as de latrocínio, ou seja, o roubo seguido de morte, que são processadas como outro tipo penal, já que implicam em outro processo judicial vinculado a crimes contra a propriedade ${ }^{19}$; lesão corporal seguida de morte; e auto de resistência, termo que originariamente se referia a um documento administrativo ${ }^{20}$. O documento era preenchido pelos policiais quando se tratava da morte de um suposto criminoso em confronto com os policiais, dispensando a confecção do auto de prisão em flagrante ou a instauração de inquérito policial nesses casos; e hoje é utilizado como título de regis-

19 Foi possível observar também uma preferência por parte dos policiais civis pelo uso da categoria "latrocínio" na tipificação das mortes ao invés de "homicídio", exatamente porque o crime passa a ser julgado por um juiz da Vara Criminal Comum e não pelo Tribunal do Júri, o que "facilitaria a condenação, pois no Júri tudo é um teatro, o advogado arma uma cena e os jurados muitas vezes acreditam no teatro que ele está fazendo. Por isso é mais difícil de provar que ele é culpado e de punir o autor. Se deixar para o juiz decidir é mais fácil condenar do que deixar para os jurados decidirem" (Delegado de Polícia Civil entrevistado para a pesquisa).

20 Ordem de Serviço “N”, n. 803, de 2 de outubro de 1969 , da Superintendência da Polícia Judiciária do Estado da Guanabara. 
tro de ocorrência. A seguir estão as orientações que aparecem nos documentos de orientação para o preenchimento do Sistema de Controle Operacional (SCO) do Programa Delegacia Le$\mathrm{gal}^{21}$ :

\section{"Morte provocada pela Ação de Terceiros}

Afastada a morte natural e a morte violenta provocada pela ação exclusiva da vítima, verificaremos a participação direta (ou indireta) de terceiros, na ação (ou omissão) que contribui para o evento morte. Em outras palavras, pelas evidências apresentadas na investigação preliminar desenvolvida na Unidade Policial, foi verificada (em tese) a existência de dolo ou culpa de terceiros. A infração penal (em tese) é identificada, devendo investir-se na apuração do fato. A escolha da infração penal entre os diversos delitos e detalhamentos da relação do sistema (SCO) norteará o caminho da complementação da investigação, inobstante a imediata identificação ou não da autoria. As opções são muitas, vejamos:

Homicídio - Homicídio Provocado por Projétil de Arma de Fogo (artigo 121 do Código Penal); $[\ldots]$

Lesão Corporal seguida de morte - Lesão Corporal seguida de morte Provocada por Pedrada (artigo $129 \S 3^{\circ}$ do Código Penal); [...]

Roubo Seguido de Morte - Roubo Seguido de Morte Provocado por Emprego de Arma Branca (artigo 157, $\S 3^{\circ}$ do Código Penal); [...];

Etc.” (SESP-RJ, 2003; grifos no original).

"O CONFRONTO POLICIAL: Nem sempre uma morte se origina de uma ação ilícita provocada pelos integrantes do tráfico de entorpecentes. Os confrontos violentos entre os órgãos repressores e os integrantes do tráfico também ocasionam vítimas, algumas fatais. Esses fatos devem ser registrados da melhor forma possível, pois essa resistência constitui uma clara demonstração de poderio de força armada dos grupos criminosos, evidenciando o alto grau de periculosidade desses segmentos delituosos. Ao resistir às incursões policiais, a resposta violenta do tráfico de entor-

21 Para uma análise do Programa Delegacia Legal, ver: Miranda (2005); Paes (2006); Miranda, Oliveira e Paes (2007); Gomes (2008); Oliveira (2008); Peixoto (2008) e Miranda, Oliveira e Paes (2010). pecentes, empregando suas armas em fogo cerrado contra os membros do aparato policial, provoca uma reação armada legal por parte dos representantes do Estado. Pode ocorrer nesse confronto a morte de algum oponente, o que não é difícil de esperar, pois seu autor se encontra sob o manto da excludente de ilicitude, instituto juridico-penal em que se acha a legítima defesa, não existindo assim, condenação para o autor da ação perpetrada, caso se configure essa modalidade" (SESP-RJ, 2005, p. 50-51; sem grifos no original).

No caso da Argentina, a categoria homicídio doloso (que inclui roubo e outros tipos de delitos cujo resultado seja a morte, tanto do autor como da vítima) e que é a categoria na qual as polícias devem completar uma planilha especial, inclui por sua vez as mortes equivalentes ao que no Rio de Janeiro (e em São Paulo) registra-se como "auto de resistência". Essa é uma questão importante, pois consta que, ao classificar os dados, as polícias resistem em registrar essas mortes com a categoria penal homicídio doloso, toda vez que consideram que é altamente discutível a intenção de matar. De fato, tanta resistência criou nas polícias essa instrução de registrar esses casos como homicídio doloso que, no Manual de Instrucciones, as orientações resumidas para os funcionários policiais encarregados do registro dos fatos aparecem os seguintes textos:

"Homicidios dolosos: comprende todos los homicidios causados en forma intencional por el imputado, ya sea homicidio simple (art. 79 C.P.), agravado (art. 80 C.P.), en estado de emoción violenta (art. 81 inc. a C.P.), homicidio preterintencional (art. 81 inc. b C.P.), homicidio en ocasión de robo (165 C.P.) y homicidio en riña (art. 95 C.P.).

Las muertes producidas por miembros de las fuerzas de seguridad en cumplimiento del deber también deben consignarse como homicidios dolosos (aunque no constituyan delito)" (DNPC, 1999a; grifos no original).

En ocasión de otro delito? (C): Ver Tablas de Codificación de Datos e Indicar sólo el número que corresponde a la categoría seleccionada (sólo UNA).

Sí, robo: cuando el homicidio se produce en ocasión de un robo o intento de robo. Incluye los casos de muertes producidas por posteriores 
enfrentamientos (en caso de robo) con la policía, sean éstos delincuentes o terceros" (DNPC, 1999b; sem grifos no original).

Uma vez que fizemos isso passamos também a construir bases equivalentes, questão que para o cruzamento de dados era especialmente necessária, já que a base de dados brasileira é uma só para fatos, vítimas e autores do fato; enquanto na Argentina tratava-se de duas bases de dados, uma para os fatos e suas características e outra para as pessoas implicadas (vítimas e autores, que com a lógica judicial que permeia o sistema são denominados "imputados"). Isso implicou não só o desenvolvimento de tarefas informáticas de certa complexidade, mas também o confronto com pessoal técnico que, nos dois lugares, mencionaram seus sistemas, suas rotinas e suas modalidades de trabalho padronizadas, que não eram simples de alterar. O certo é que, conforme avançava o trabalho de investigação ficou cada vez mais evidente que essa tarefa prévia de explicar os processos de produção de informação levava a uma etnografia da produção de estatísticas oficiais de criminalidade. Uma tarefa na qual, como se disse por todos os participantes deste projeto de pesquisa, além de cientistas sociais, desempenharam papéis em distintos momentos, como funcionári- os públicos diretamente ligados às tarefas de construção de sistemas de classificação de crimes e outras formas de registros policiais e à produção de informação no ISP e na DNPC, ou seja, nós fomos especialmente afetados (FAVRET-SAADA, 2005; MIRANDA, 2010).

\section{OS DADOS OFICIAIS}

Conforme desenvolvemos anteriormente, ao partirmos do princípio de que as estatísticas não mentem e nem dizem a verdade, buscamos compreender seus processos de produção para tentar construir comparações entre as informações divulgadas oficialmente sobre as regiões metropolitanas de Buenos Aires e Rio de Janeiro, tendo em vista que a temática da gestão da informação 22 tem sido considerada contemporaneamente um dos "pressupostos" para uma política de segurança eficiente e transparente.

A primeira consideração relevante é que, enquanto a região metropolitana de Buenos Aires (RMBA) é maior em termos de população, com cerca de 12198207 de pessoas em 2005, comparada com os 10973530 de pessoas estimadas para a área metropolitana do Rio de Janeiro (RMRJ), o número de homicídios é muito maior, onde em um ano o total de vítimas excede o montante de vítimas em quatro anos de RMBA.

TABELA 1 - VÍTIMAS DE HOMICÍDIOS REGISTRADOS NAS REGIÕES METROPOLITANAS DO RIO DE JANEIRO E DE BUENOS AIRES (2002-2005)

\begin{tabular}{|l|c|c|c|c|}
\hline \multirow{2}{*}{ ANO } & \multicolumn{2}{|c|}{ VíTIMAS - VALORES ABSOLUTOS } & \multicolumn{2}{c|}{$\begin{array}{c}\text { VíTIMAS - TAXAS POR 100 MIL } \\
\text { HABITANTES }\end{array}$} \\
\cline { 2 - 5 } & RIO DE JANEIRO & BUENOS AIRES & RIO DE JANEIRO & BUENOS AIRES \\
\hline 2002 & 6707 & 1769 & 63,04 & 14,78 \\
2003 & 6939 & 1273 & 64,54 & 10,57 \\
2004 & 6435 & 838 & 59,24 & 6,92 \\
2005 & 6457 & 759 & 58,84 & 6,22 \\
TOTAL & 26538 & 4639 & 245,66 & 38,49 \\
\hline
\end{tabular}

FONTES: as autoras, a partir de DNPC (s/d) e ISP-RJ (s/d).

22 A gestão da informação geralmente está associada à estruturação de formas de acesso e difusão da informação. Embora não seja o escopo deste trabalho, é preciso salientar que há uma grande discussão sobre as diferenças entre gestão da informação e gestão do conhecimento. O que se pode identificar no que se refere ao debate na área de segurança é que os modelos propostos partem da idéia de uma complexificação progressiva: Dados $\rightarrow$ INFORMAÇÃO $\rightarrow$ CONHECIMENTO (MIRANDA, no prelo) 
TABELA 2 - CASOS DE HOMICÍDIOS REGISTRADOS NAS REGIÕES METROPOLITANAS DO RIO DE JANEIRO E DE BUENOS AIRES (2002-2005)

\begin{tabular}{|l|c|c|c|c|}
\hline \multirow{2}{*}{ ANO } & \multicolumn{2}{|c|}{ DADOS - VALORES ABSOLUTOS } & \multicolumn{2}{c|}{ DADOS - TAXA POR 100 MIL HA BITANTES } \\
\cline { 2 - 5 } & RIO DE JANEIRO & BUENOS AIRES & RIO DE JANEIRO & \multicolumn{2}{c|}{ BUENOS AIRES } \\
\hline 2002 & 5893 & 1707 & 55,39 & 14,27 \\
2003 & 6106 & 1239 & 56,79 & 10,29 \\
2004 & 5580 & 808 & 51,37 & 6,67 \\
2005 & 5586 & 736 & 50,90 & 6,03 \\
TOTAL & 23165 & 4490 & 214,46 & 37,26 \\
\hline
\end{tabular}

FONTES: as autoras, a partir de DNPC (s/d) e ISP-RJ (s/d).

Outro aspecto relevante é que nas duas regiões observou-se uma diminuição de registros de homicídios nas taxas por 100000 habitantes, mas a escala do fenômeno é claramente divergente, tendo uma média no período analisado de 61,42 vítimas na RMRJ e 9,62 vítimas para a RMBA. Talvez, essas escalas muito diferentes possibilitem destacar as diferenças que fazem uma matriz de sociabilidade diferente, na qual a extrema violência expressa uma maneira de resolução de con- flitos predominante. Pode-se notar, no entanto, que em ambas as regiões a razão entre os fatos e as vítimas é, muitas vezes 1:1, ou seja, a relação entre fatos/vítimas para a RMRJ foi 1:14 vítimas por fato e na RMBA foi de 1:03. Tal observação permite afirmar que essas mortes possuem uma natureza interpessoal, mas como não se pode identificar a motivação do crime, é possível ao menos afirmar que não se tratam de mortes em massa ou em série.

TABELA 3 - SUPOSTOS AUTORES DE HOMICÍDIOS REGISTRADOS NAS REGIÕES METROPOLITANAS DO RIO DE JANEIRO E DE BUENOS AIRES (2002-2005)

\begin{tabular}{|l|c|c|c|c|c|}
\hline REGIÃO METROPOLITANA & $\mathbf{2 0 0 2}$ & $\mathbf{2 0 0 3}$ & $\mathbf{2 0 0 4}$ & $\mathbf{2 0 0 4}$ & TOTAL \\
\hline Rio de Janeiro & 5605 & 5985 & 5419 & 5985 & 22994 \\
Buenos Aires & 1188 & 798 & 657 & 591 & 3234 \\
\hline
\end{tabular}

FONTES: as autoras, a partir de DNPC (s/d) e ISP-RJ (s/d).

Quando se analisa a razão entre fatos e autores, entendidos como as pessoas inicialmente identificadas como responsáveis pela autoria do crime na fase de investigação policial, observa-se que na RMRJ a existência de supostos autores indiciados pelos oficiais de polícia foi de 0,99 enquanto na RMBA foi de 0,72 . Vale ressaltar que no caso do Rio de Janeiro essa relação não significa o indiciamento, mas sim que ao abrir um inquérito de homicídio o sistema pressupõe a existência de um autor, mesmo que ele não seja identificado e muito menos indiciado pela polícia.

GRÁFICOS 1-4 - LOCAL DO FATO DAS MORTES VIOLENTAS REGISTRADAS
NAS REGIÕES METROPOLITANAS DO RIO DE JANEIRO E DE BUENOS AIRES (2002-2005)

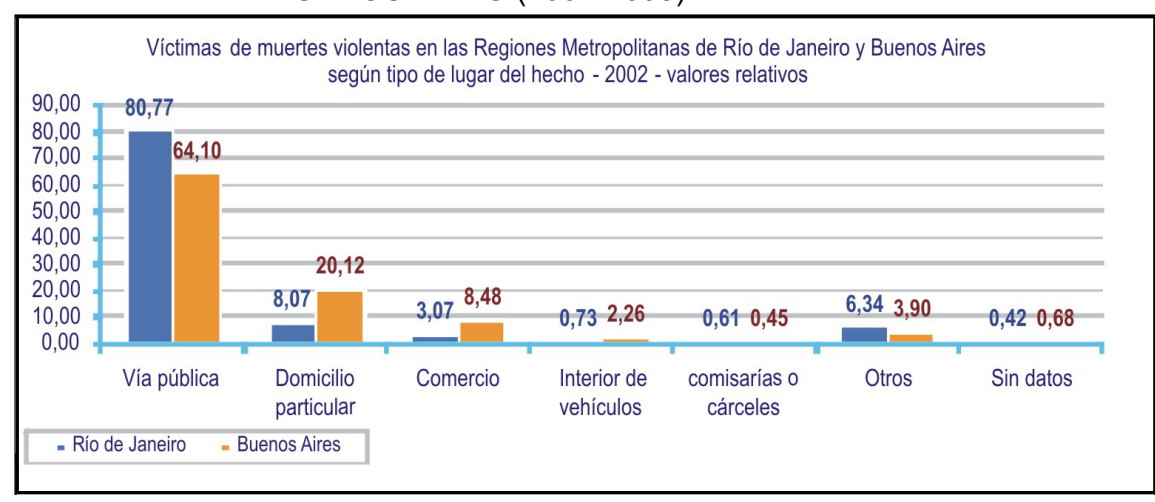




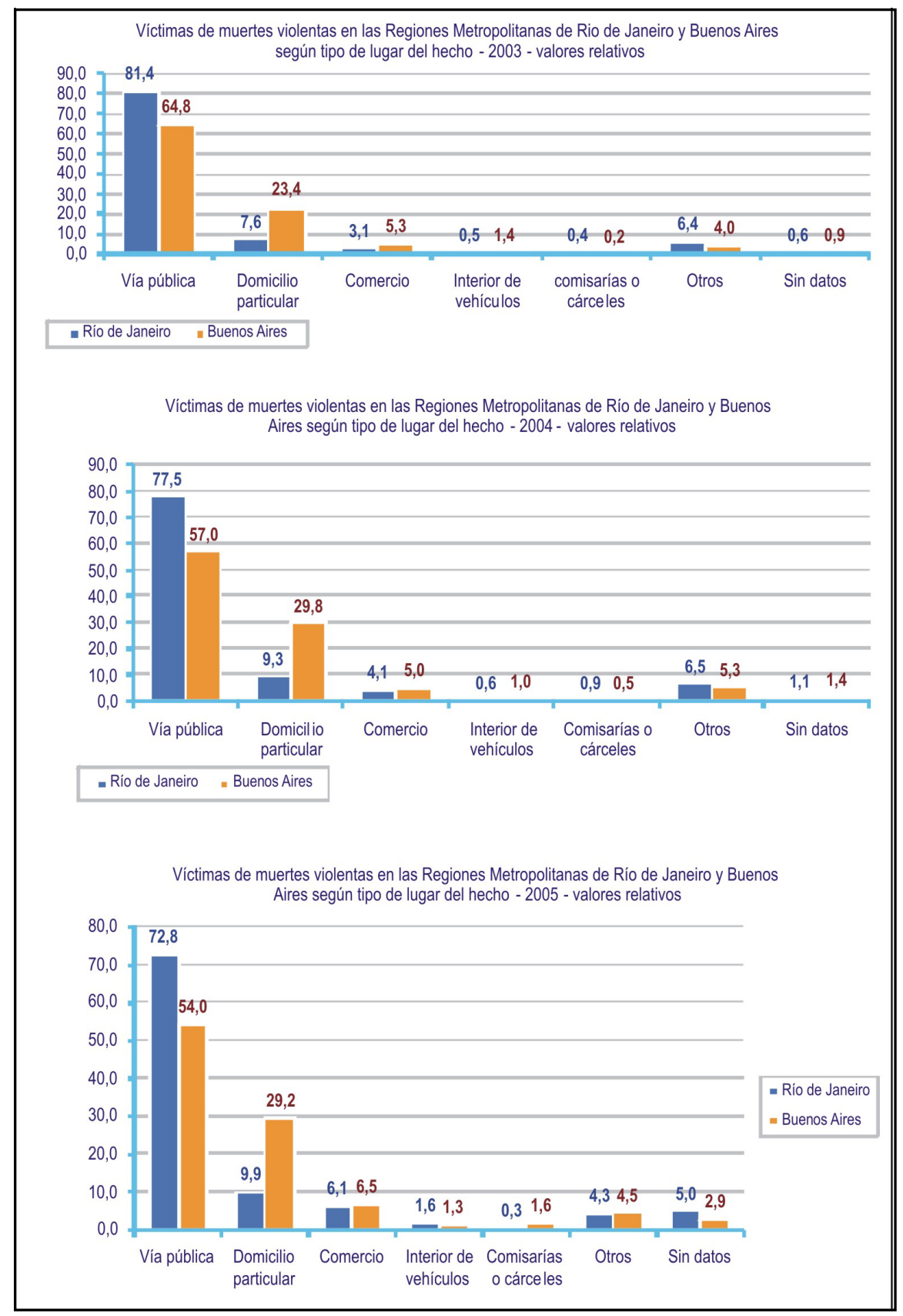

FONTES: as autoras, a partir de DNPC (s/d) e ISP-RJ (s/d).

Os casos de morte violenta nas duas regiões metropolitanas revelam que os eventos ocorreram principalmente na "via pública" ou em áreas de menor espaço de privacidade ou intimidade (valor que pode ser aumentado se forem tratados como categorias agregadas à via pública e ao comércio), o que realmente poderia levar a pensar sobre os usos dos espaços públicos, mas também e principalmente a indagar que tipo de lugares são classificados nesta categoria genérica de via pública, levando-se em consideração que a "rua" tem sig- nificados e usos distintos em favelas, "villas" $23 \mathrm{e}$ bairros pobres daqueles existentes em bairros residenciais, característicos das classes médias,

23 Villa de emergencia ou Villa miseria é o termo utilizado na Argentina para se referir a bairros muito pobres, de viviendas precárias e infraestrutura deficiente surgidos sem planificacao oficial. No seu interior tem ruelas ou corredores muito estreitos ("pasillos") por onde as pessoas circulam. 
sendo o primeiro um espaço público de alta concentração de pessoas, moradores ou passantes, que é integrado socialmente às rotinas da comunidade, de modo muito diferente de bairros residenciais ou das áreas centrais, mais voltadas às atividades comerciais. $\mathrm{O}$ aprofundamento dessa análise demandaria uma desagregação territorial de dados, o que não foi possível para os dados compilados.

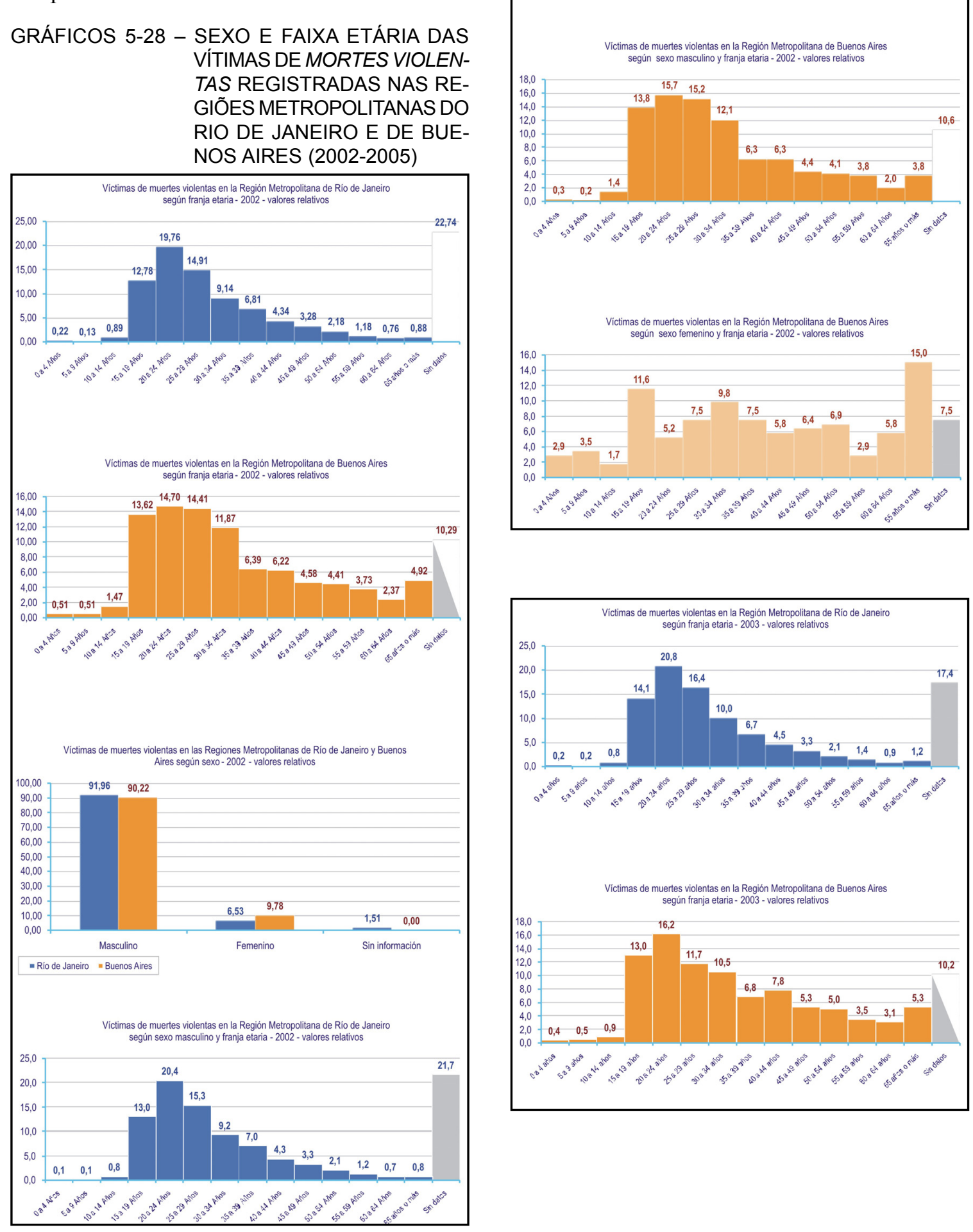



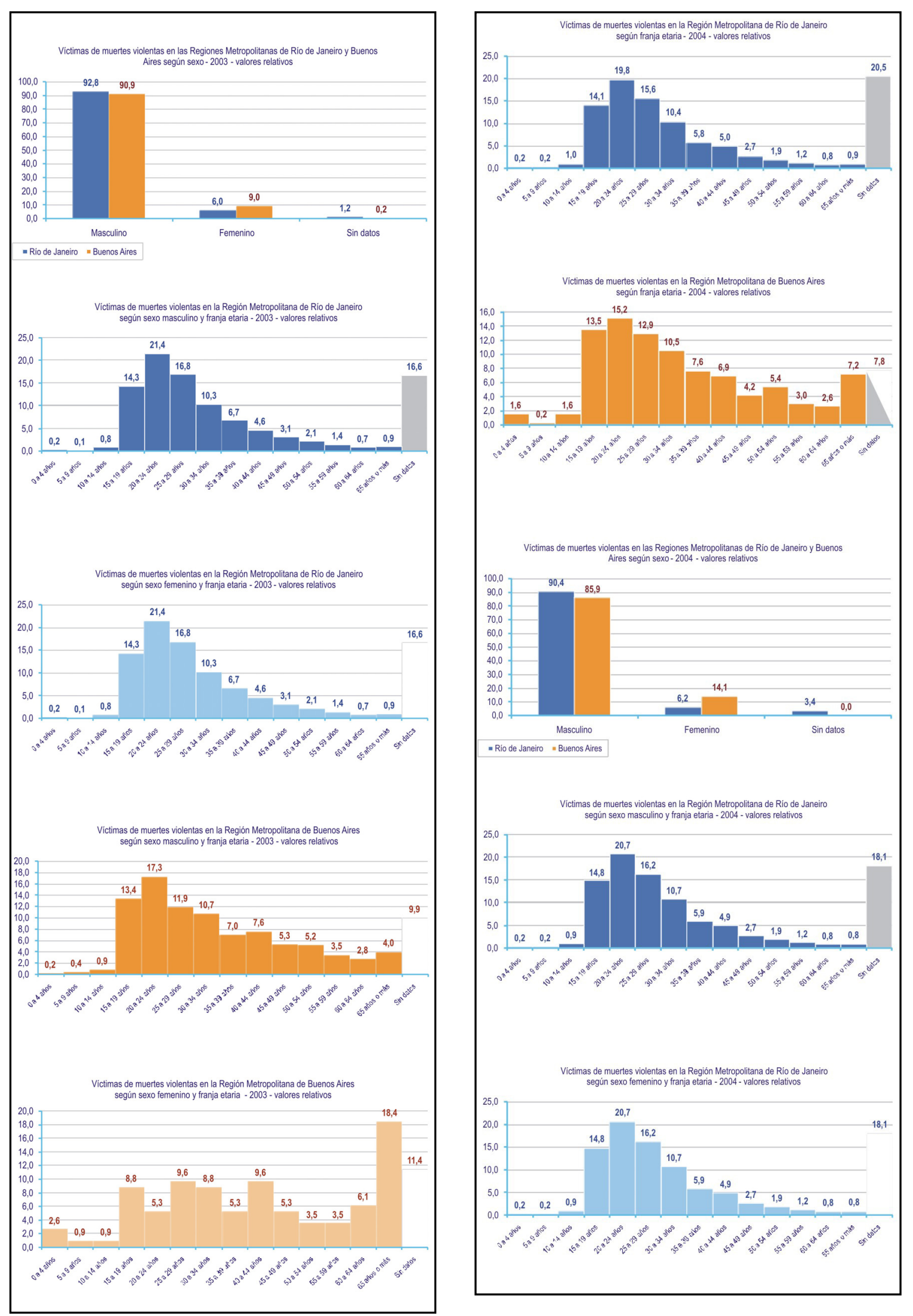

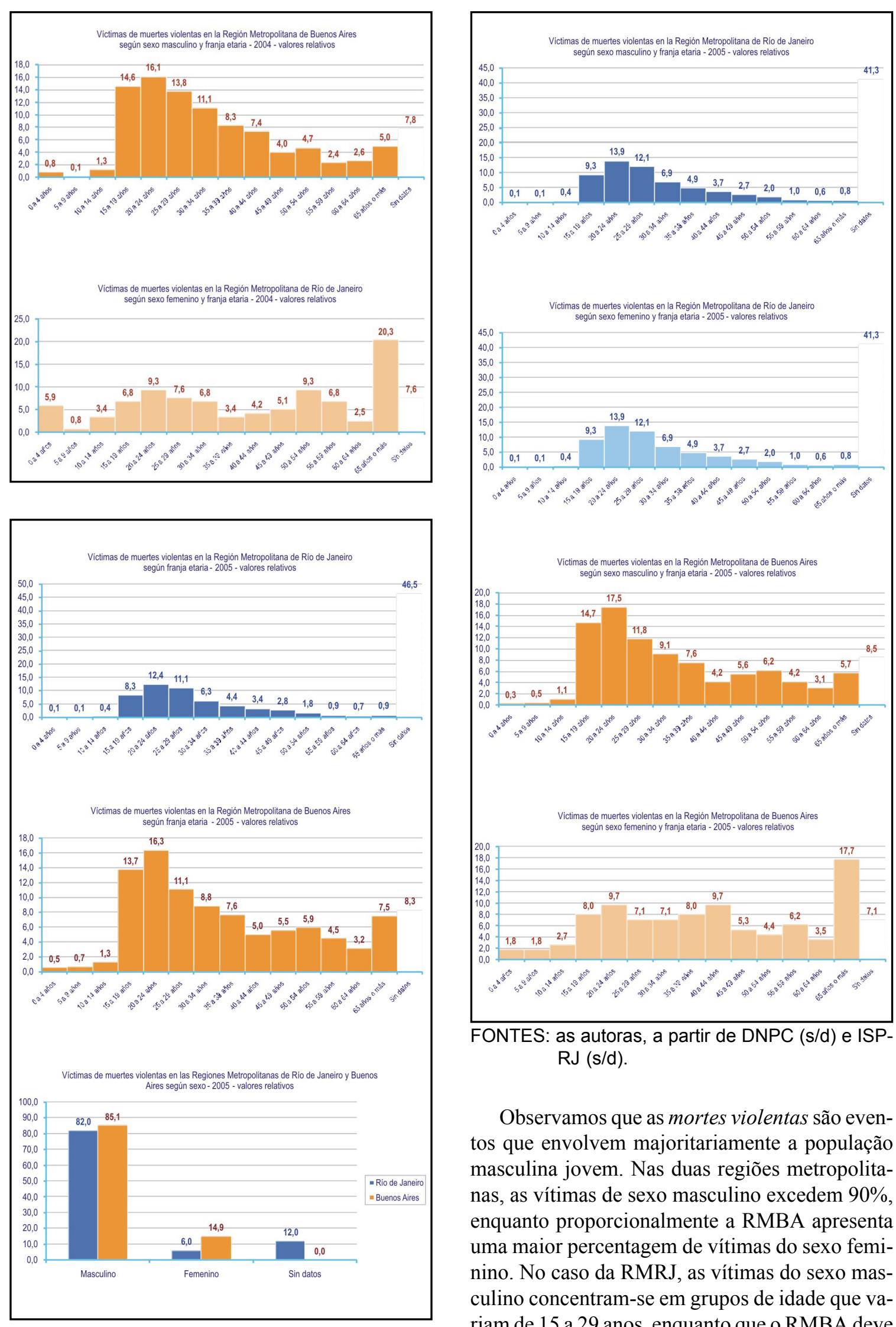

FONTES: as autoras, a partir de DNPC (s/d) e ISP$\mathrm{RJ}(\mathrm{s} / \mathrm{d})$.

Observamos que as mortes violentas são eventos que envolvem majoritariamente a população masculina jovem. Nas duas regiões metropolitanas, as vítimas de sexo masculino excedem $90 \%$, enquanto proporcionalmente a RMBA apresenta uma maior percentagem de vítimas do sexo feminino. No caso da RMRJ, as vítimas do sexo masculino concentram-se em grupos de idade que variam de 15 a 29 anos, enquanto que o RMBA deve 
incluir também o grupo de idade após os 34 anos. No entanto, para RMBA deve-se considerar a distribuição das vítimas mulheres por grupo etário, assim se pode ver que ela é muito diferente dos padrões da população masculina. Para as mulheres, as maiores percentagens concentram-se em grupos de idade que se pode chamar de extremas, estando em primeiro lugar o grupo de idade de 65 anos ou mais (15\%), seguido pelo grupo de 15 19 anos (11,6\%). Entre as vítimas mulheres na RBMA, destaca-se também uma participação nãonegligenciável de grupos de idade de mulheres que variam de zero a nove anos $(5,5 \%)$.

Existe uma forte coincidência na concentração das percentagens de vítimas, $82 \%$ e $85 \%$ dos homens no Rio de Janeiro e em Buenos Aires, respectivamente. Porém, ressalta-se que no caso da Região Metropolitana de Buenos Aires a percentagem de homens subiu para $92 \%$. Em relação à idade das vítimas, é uma coincidência o elevado número de casos de pessoas menores de 26 anos. Na Região Metropolitana do Rio de Janeiro, 22,5\% das vítimas estavam concentradas na faixa etária entre 18 e 26 anos, enquanto em Buenos Aires essa percentagem sobe para $29 \%$. Outro ponto importante é que não há nenhuma informação em $12 \%$ dos casos no Rio de Janeiro, o que poderia indicar um problema relativo à qualidade das informações que constam nos registros de ocorrências.

TABELAS 4 E 5 - HOMICÍDIOS PROVOCADOS POR ARMA DE FOGO REGISTRADOS NAS REGIÕES METROPOLITANAS DO RIO DE JANEIRO E DE BUENOS AIRES (2002-2005)

SÉRIE ANUAL DE VÍTIMAS DE HOMICÍDIOS PROVOCADOS POR ARMA DE FOGO

\begin{tabular}{|l|c|c|c|c|}
\hline REGIÃO METROPOLITANA & $\mathbf{2 0 0 2}$ & $\mathbf{2 0 0 3}$ & $\mathbf{2 0 0 4}$ & $\mathbf{2 0 0 5}$ \\
\hline Rio de Janeiro & 5611 & 5891 & 5341 & 5265 \\
Buenos Aires & 1398 & 990 & 549 & 489 \\
\hline
\end{tabular}

PERCENTUAL DE PARTICIPAÇÃO DAS ARMAS DE FOGO SOBRE O TOTAL DE VÍTIMAS DE HOMICÍDIOS

\begin{tabular}{|l|c|c|c|c|}
\hline REGIÃO METROPOLITANA & $\mathbf{2 0 0 2}$ & $\mathbf{2 0 0 3}$ & $\mathbf{2 0 0 4}$ & $\mathbf{2 0 0 5}$ \\
\hline Rio de Janeiro & 83,7 & 84,9 & 83,0 & 81,5 \\
Buenos Aires & 79,0 & 77,8 & 65,5 & 64,4 \\
\hline
\end{tabular}

FONTES: as autoras, a partir de DNPC (s/d) e ISP-RJ (s/d).

Pelos dados é possível observar que se o total de casos e a taxa de vítimas de homicídio são significativamente diferentes nas duas Regiões Metropolitanas, a evolução do número de casos registrados durante os anos estudados apresenta semelhanças. A maioria dos homicídios registrados em ambos os locais foi cometida com uso de armas de fogo.

No entanto, a percentagem de casos com armas de fogo durante o ano de 2005 foi a menor de toda a série em ambos os casos, destacandose o que aconteceu em Buenos Aires, onde a percentagem diminuiu de $81 \%$ para $64,4 \%$ em 2005 . Embora esses dados sejam meramente indicativos, sendo necessário um aprofundamento para saber sobre as possíveis razões para esse comportamento, seria interessante relacionar os outros tipos de armas usadas nesses modos ou circunstâncias em que as mortes foram produzidas, o que não foi possível devido à limitação de qualidade das informações.

No que se refere à RMRJ, entre os anos de 2001 a 2003, houve um aumento da participação do uso de armas de fogo no Rio de Janeiro, que passou a cair a partir de 2004. Embora não seja possível demonstrar com base nessas informações, é importante ressaltar que nesse período entrou em vigor no Brasil o Estatuto do Desarmamento, que além de aumentar as restrições para porte e uso de armas, implantou uma política de recompensa financeira para quem entregasse suas armas. No caso da RMBA é possível notar que a tendência de queda está presente desde o ano de 2001. 
GRÁFICOS 29-32 - PROPORÇÃO ENTRE VÍTIMAS DE MORTES VIOLENTAS E ROUBOS REGISTRADOS NAS REGIÕES METROPOLITANAS DO RIO DE JANEIRO E DE BUENOS AIRES (2002-2005)

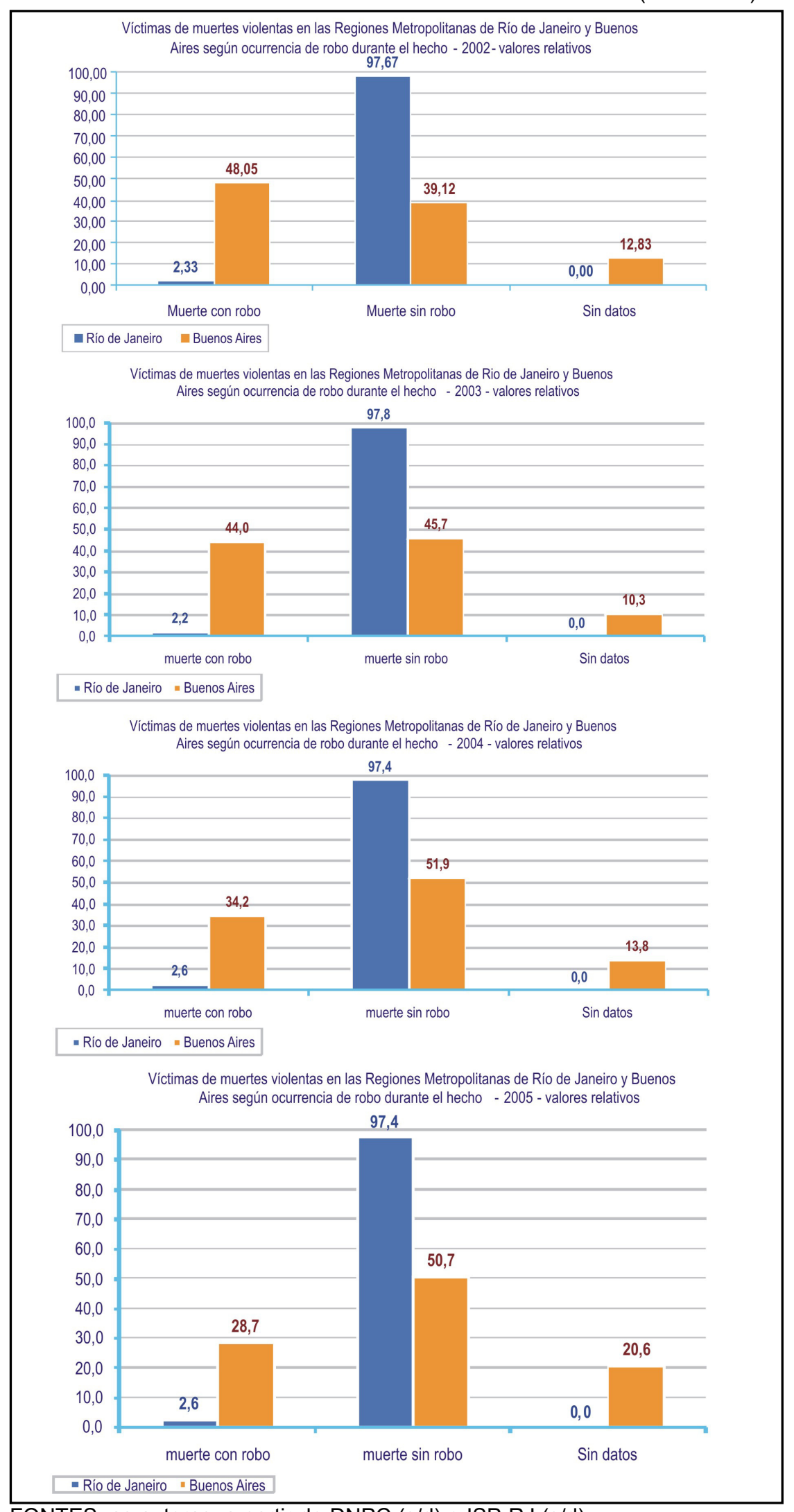

FONTES: as autoras, a partir de DNPC (s/d) e ISP-RJ (s/d). 
É notável que a RMRJ seja onde se tem a maior percentagem de mortes violentas em eventos nos quais não houve nenhum roubo $(97,4 \%$ para 2005 contra 50,7 por cento para RMBA), ressaltando-se que na RMBA nesse ano não havia informação sobre $20,6 \%$ no que se refere às circunstâncias do evento.

Assim, para a RMRJ apenas $2,6 \%$ das vítimas foram mortas em situação de roubo, enquanto no RMBA foram $28,7 \%$. Por conseguinte, é importante observar que a maior parte das mortes violentas não estão relacionadas ao cometimento de outro delito, sendo altamente provável inferir que uma elevada percentagem de eventos ocorreu entre as pessoas com algum grau de relacionamento anterior.

Neste ponto, em função dos dados apresentados, têm-se algumas afirmações, alguns pressupostos e novas perguntas: as mortes violentas registradas não parecem resultar de situações de roubo, que são classificados como crimes contra a propriedade, mas sim parecem estar relacionadas a outro tipo de eventos que envolvem a morte, que se tornam o resultado de um conflito, de qualquer daqueles envolvidos no evento. Por essa razão, pelo menos um percentual significativo de casos deve ser separado dos atos de violência extrema em situações de roubo de rua. No entanto, a maioria das vítimas é morta em resultado do uso de armas de fogo, o que evidencia em grande medida a existência, a circulação e a utilização de armas - independentemente do status de sua posse, legal ou ilegal. Essas mortes são evidências claras de formas violentas de resolução de conflitos. Mas a que tipo de conflito as mortes referem-se? Conflitos entre conhecidos? Conflitos de vizinhança? Conflitos cotidianos que transcendem aos limites tolerados socialmente de violência física? Quantos desses conflitos têm encontrado essa forma extrema de resolução com a eliminação do outro? Em que medida tais eventos e suas características podem levar-nos a pensar que as mortes violentas correspondem menos a uma forma própria de resposta a crimes contra a propriedade, mas sim a um tipo de sociabilidade, uma forma de relacionamento que ultrapassa e excede uma dinâmica criminosa prévia do qual a morte violenta é uma consequência? Podese pensar que elas são resultados de ajustes e desacordos - dos mais variados tipos - dos quais resultam uma resolução pensada, possível e evidente? Se esse fosse o caso, que tipo de política pública deve ser considerado para a sua redução que não esteja centrado na lógica da "luta para o crime"?

\section{CONSIDERAÇÕES FINAIS}

Desde o início este trabalho implicou o reconhecimento de um fato: toda vez que se propusesse a produzir dados e dar conta do processo de produção de estatísticas estatais em matéria de criminalidade, dever-se-ia trabalhar observando várias dimensões dos registros. Isso ocorria porque ao tratar-se da produção de estatísticas oficiais, ou seja, de estatísticas como saberes legítimos do Estado, está-se lidando diretamente com uma "linguagem do Estado". Uma linguagem que ao mesmo tempo é resultado e/ou efeito das ações, decisões e "formas de pensar o mundo" de uma burocracia, que possui em si mesmo um sentido, uma significação ${ }^{24}$ e que porta uma ampliação de valor: a "estatalidade" 25 . Essa afirmação, que poderia dizer respeito à produção de conhecimento, em geral, nos âmbitos do Estado, em nosso campo específico de interesse, a segurança pública, 24 Sobre a distinção entre "sentido" e "significação", ver
Oliveira (2000).

25 Embora desenvolver essa questão in extenso aqui nos desviaria demasiadamente dos objetivos deste artigo, não queremos deixar de mostrar de um modo sintético que sentido damos à noção de "estatalidade". Quando falamos de estatalidade nos referimos a um acréscimo de autoridade que reveste as ações de certos indivíduos e/ou grupos de pessoas. Neste sentido incorporamos a premissa metodológica de Radcliffe-Brown que o leva a afirmar que "o Estado é uma ficção dos filósofos". Sustentar isto não implica subtrair seu poder, muito pelo contrário, já que se trata de una fição poderosa. Mas permite advertir que o Estado não é nem uma "coisa" com vontade própria e supra-individual, nem tampouco uma "abstração legal", mas sim o efeito de um grupo das pessoas, de repartições, de leis, regulamentos, que encarnam a autoridade de essa ficção, ou seja, investidos de estatalidade. Conforme afirmou Radcliffe-Brown (1970, p. xxxiii), "o que existe é uma organização, isto é, um grupo de seres humanos ligados por um sistema complexo de relações. Dentro desta organização diferentes indivíduos desempenham diferentes papéis, e alguns detêm um poder especial ou autoridade, como chefes ou anciãos capazes de dar ordens que serão obedecidas, como legisladores ou juízes, e assim por diante. O poder do Estado é coisa que não existe; há apenas na realidade, poderes de indivíduos - reis, primeiros-ministros, magistrados, polícias, chedes de partido e votantes". Concordando com essa leitura, Melossi (1992) nos recorda que Weber sustenta a importância de compreender como os indivíduos, com suas ações fazem as organizações e instituições que, por sua vez, dão um caráter de pessoas fictícias e que, agrupadas sobre a "idéia de Estado", constituem-no. 
envolve diferentes "especialistas", com saberes, interesses e capacidades de poder diversas: cientistas sociais, policiais e funcionários políticos, ou seja, aqueles que ocupam cargos em função de uma indicação política. Todos eles envolvem-se na produção de uma informação que, por um lado reflete processos de trabalho que vão desde a descoberta (pela via da queixa - policial ou judicial ou a investigação policial) de um fato até a construção de um caso que se converterá em um dado; e proverá elementos para pensar "a realidade" e o "clima social" referidos à criminalidade e a violência social, que de maneira concomitante incidem sobre a formulação de políticas públicas, ao menos na pretensão de sua formulação.

Essa última questão não é um assunto banal, já que especialmente nesse campo, tanto os "climas sociais" que necessariamente ligam-se às demandas da população, como as pretensões de respostas rápidas dos "poderes políticos", especialmente sensíveis a elas, têm nos dado um especial objeto de interesse e também de disputa. Quer dizer, embora a questão do crime não seja nova, a forma como tem articulado-se o tema com as demandas por segurança nas últimas décadas tem levado a consolidar-se um campo de "opinião" ou de "demanda social" relativamente difusa, mas fortemente poderosa e que incide de maneira eficaz não apenas em definir os assuntos da agenda pública, mas de impor a forma de interpretar os fatos e, conseqüentemente, demandar respostas urgentes e rápidas. As intervenções ativas que se poderia denominar, segundo Darío Melossi, de elites morais, "aqueles que estão autorizados para identificar e rotular os problemas sociais e que em conseqüência operam para controlar uma situação que percebem como ameaçadora para as bases políticas, sócio-econômicas e culturais que identificam com a "defesa e promoção de sua própria hegemonia"26 (MELOSSI, 1992, p. 43), sem

26 Ao esboçar o tema nestas condições, Darío Melossi leva o olhar mais além do que “o Estado 'faz' ou 'deixa de fazer'”, estendendo sua análise de maneira que seja possível considerar a intervenção de "grupos, de organizações e de indivíduos, assim como de outros atores sociais, que tem razões e fundamentos para suas próprias ações", de elites morais "[...] indivíduos e grupos que dentro de pautas dadas, têm êxito em expressar as posições morais que eventualmente se transformarão em hegemônicas, frequentemente através do conflito. Mais especificamente, eles têm êxito em reclamar sua 'propriedade' [...] sobre áreas específicas da vida social” (MELOSSI, 1992, p. 43). dúvida contribuem para criar cenários nos quais o poder político e as agências estatais envolvidas devem responder com urgência diante "do que acontece". Criados esses climas sociais, os dados resultam em um elemento de combate com alto valor político.

Tornou-se claro que seria necessário também dar conta da articulação da burocracia com o poder político. O "valor político" dos dados produzidos por essa burocracia particular tratava-se de um espaço privilegiado para dar conta das tensões e conflitos entre a produção de conhecimento e as razões de Estado. Assim, ficou evidente que o campo de trabalho implicava atender a essas várias dimensões (PANTALEÓN, 2004) que produzem a configuração de uma racionalidade própria, expressa por uma dimensão técnica (legitimada "cientificamente" mediante processos unificados de medições), alimentada por una $d i$ mensão cognitiva experta (aquela que faz a construção de categorias classificatórias e taxonomias resultantes de um saber prático - policial - bem como a vinculação entre esse saber prático e os códigos legais - o código penal), e uma dimensão politica (produzida pela articulação, muitas vezes conflituosa, das perspectivas e do trabalho dos burocratas, dos funcionários políticos e dos cientistas sociais, que buscam definir e impor determinados modos de medir e ler os fenômenos sociais que, por sua vez, ao serem transformados em dados, resultam em insumos para o diagnóstico de situações e para a formulação de políticas públicas) (GUEDES, 2008; MIRANDA \& DIRK, 2010; PITA \& OLAETA, 2010; MIRANDA, no prelo). Compreender essas dimensões é fundamental porque as classificações do Estado são a materialização de relações de poder, portanto o que resulta de uma disputa, questão que mais de uma vez fica obscurecida e/ou eventualmente apresentada como um problema metodológico, o que leva a discussão a outro tipo de debate, um debate "técnico".

No caso particular das estatísticas de criminalidade, elas têm recebido dois grandes questionamentos: que existe um alto número de eventos que não ingressam ao sistema, e que há una seletividade nos casos que são reportados. $\mathrm{O}$ que se pode afirmar é que a estatística oficial de criminalidade surge de um processo complexo de construção da informação em que diferentes atores pertencentes a organismos produtores de dados devem tomar uma série de decisões que 
implica recortes ou suspeitas sobre os números informados. Assim, trata-se de informações que refletem a atuação da agência, sua forma particular de tratar o fenômeno, expressando limites que refletem, entre outras questões, em seu próprio campo de atuação. A estatística oficial sobre criminalidade surge do próprio registro que fazem os organismos integrantes do sistema de justiça sobre sua própria área de competência. Em um sentido amplo, pode-se dizer que os dados oficiais abarcam as polícias e forças de segurança, o poder judiciário, o ministério público e os serviços penitenciários. No que se refere ao registro de delitos em particular, as estatísticas policiais e de forças de segurança são as que representam a cifra oficial. Em suma, as estatísticas policiais mostram o estado da criminalidade de acordo com os critérios e as concepções das próprias agências de segurança; tomando como base o registro originado nas denominadas atividades de prevenção, que realizam as polícias nas ruas ou por meio de reclamações particulares efetuadas nas delegacias. Foi conhecendo esse processo de produção, analisando as categorias e seu alcance, que conseguimos gerar esses dados que aqui expomos.

Ter realizado uma pesquisa dessa natureza não fez duvidar da validade científica da informação quantitativa, nem desistir de considerá-la no momento de avançar em descrições e análises a respeito dos fatos que resultam em mortes violentas. Ao contrário, ao descrever seu complexo processo de produção, acreditamos que foi possível avançar não apenas na geração de informação consistente e comparável, mas principalmente em dar conta daquilo que está cifrado nas cifras, ou seja, o resultado cristalizado de rotinas burocráticas e sensibilidades. Acredita-se que a articulação das metodologias qualitativa e quantitativa possibilita romper com uma visão positivista corrente de que os "dados" estão na realidade prontos a serem "coletados", o que nega uma oposição vigente no senso comum entre os métodos quantitativos e qualitativos como modos opostos e inconciliáveis de ver a realidade.

Uma questão adicional que excede o limite de nosso trabalho, mas não deve ser perdida de vista, é a legitimidade social da autoridade que valida os dados em um ato de fé pública, tendo em vista que questão é a confiança pública no Estado. É importante lembrar que há uma enorme tradição de desconfiança e falta de credibilidade a respeito de qualquer indicador proveniente do circuito de produção de informações e estatísticas oficiais (O’DONNELL, 1997).

No caso das estatísticas oficiais sobre mortes violentas é relevante destacar que, no Rio de Janeiro, foi possível observar um processo de desvalorização da categoria homicídio a partir da análise das distinções entre os casos atendidos pelos policiais entre aqueles considerados "crimes de verdade" e conflitos "menores", comumente chamados entre os policiais de "feijoada" (SOUZA, 2008). Os "crimes de verdade" estariam relacionados aos crimes contra o patrimônio, como grandes assaltos e tráfico de drogas, enquanto os homicídios apenas se destacariam quando fossem "crimes de repercussão", ou seja, o fato poderia ganhar destaque na mídia em função da natureza do morto, o que lhe garantiria um tratamento diferenciado no âmbito policial, pois esse é um dos critérios para que um caso seja requisitado nas Delegacias de Homicídios . Tal fato é mais uma demonstração de que as rotinas relacionadas ao registro de uma morte violenta revelam uma diversidade de interpretações das normas legais que explicitam uma sensibilidade jurídica (GEERTZ, 2006) própria, marcada por uma tradição inquisitorial de construção da verdade, na qual o segredo, a suspeição e a desigualdade jurídica são os princípios básicos de intervenção. Isso conflita com um modelo da transparência e publicidade dos dados, que orienta as atuais políticas públicas de segurança, denominadas de "gestão da informação", segundo as quais a informação estaria associada a formas pré-estabelecidas de análise, que pressupõem algum consenso sobre os significados atribuídos ao fato e o compartilhamento do conhecimento construído, para que possam ser legitimados socialmente.

A comparação das diferenças entre os modos de registrar, buscando eventuais equivalências, possibilitou perceber que a variedade das classificações relativas às mortes violentas é reveladora de representações que qualificam a morte em função não só da intencionalidade do ato, como prevê a legislação, mas também em função da natureza do morto, delimitando assim a existência de "seres matáveis" (PITA, 2010), o que pode ser pensado como uma legitimação da morte e uma forma de administração institucional e informal de conflitos. 
Ana Paula Mendes de Miranda (ana_paulamiranda@yahoo.com.br; amiranda@isp.rj.gov.br) é Doutora em Antropologia Social pela Universidade de São Paulo (USP), Professora do Programa de Pós-Graduação em Antropologia da Universidade Federal Fluminense (UFF) e Coordenadora-Executiva do Núcleo Fluminense de Estudos e Pesquisas (Nufep).

María Victoria Pita (mariapita@gmail.com) é Professora Adjunta do curso de Ciencias Antropológicas da Universidad de Buenos Aires (UBA, Argentina) e Investigadora Adjunta do Consejo Nacional de Investigaciones Científicas y Técnicas (Conicet).

\section{REFERÊNCIAS BIBLIOGRÁFICAS}

BARTH, F. 2000. Metodologias comparativas na análise dos dados antropológicos. In: O guru, o iniciador e outras variações antropológicas. Rio de Janeiro: Contra Capa.

BORGES, D. \& DIRK, R. 2006. Compreendendo os dados de violência e criminali-dade. In: MIRANDA, A. P. M. \& TEIXEI-RA, P. A. S. (orgs.). Polícia e comunidade: temas e desafios na implantação de conselhos comunitários de segurança. Rio de Janeiro: Instituto de Segurança Pública.

DIRK, R. C. 2007. Homicídio doloso no Estado do Rio de Janeiro: uma análise sobre os registros de ocorrência da Polícia Civil. Rio de Janeiro. Dissertação (Mestrado em Estudos Populacionais e Pesquisa Social). Escola Nacional de Ciências Estatísticas.

FAVRET-SAADA, J. 2005. Ser afetado. Cadernos de Campo, São Paulo, ano 14, n. 13, p. 155-162. Disponível em: http:// www.fflch.usp.br/da/cadcampo/ed_ant/ revistas_completas/13.pdf. Acesso em: 15.set.2011.

GEERTZ, C. 2006. O saber local: fatos e leis em uma perspectiva comparativa. In: . $O$ saber local: novos ensaios em Antropologia Interpretativa. $8^{\mathrm{a}}$ ed. Petrópolis: Vozes.

GOMES, A. S. 2008. Transparência, democratização e otimização das informações com a Implantação do sistema informatizado da Delegacia Legal. In: MIRANDA, A. P. M. \& LIMA, L. L. G. (orgs.). Politicas públicas de segurança, informação e análise criminal. Niterói: UFF.

GUEDES, S. 2008. O sistema classificatório das ocorrências na Polícia Militar do Rio de Janeiro e a organização da experiência policial: uma análise preliminar. In: PINTO, A. S. \& RIBEI-
RO, L. M. L. (orgs.). A análise criminal e o planejamento operacio-nal. Rio de Janeiro: Rio-Segurança.

KANT DE LIMA, R. 1995. A polícia da cidade do Rio de Janeiro: seus dilemas e paradoxos. $2^{\mathrm{a}}$ ed. Rio de Janeiro: Forense.

KANT DE LIMA, R.; MISSE, M. \& MIRANDA, A. P. M. 2000. Violência, criminalidade, segurança pública e justiça criminal no Brasil: uma bibliografia. $B I B$, Rio de Janeiro, n. 50 , p. $45-123,2^{\circ}$ semestre.

MELOSSI, D. 1992. El Estado del control social. Un estudio sociológico de los conceptos de Estado y control social en la conformación de la democracia. Ciudad de México: Siglo XXI.

MINAYO, M. C. S. 2009. Seis características das mortes violentas no Brasil. Revista Brasileira de Estudos de População, São Paulo, v. 26, n. 1, p. 135-140, jan.-jun. Disponível em: http://www.scielo.br/pdf/rbepop/v26n1/ v26n1a10.pdf . Acesso em: 15.set.2011.

MIRANDA, A. P. M. 2000. Cartórios: onde a tradição tem registro público. Antropo-lítica, Niterói, v. 8, p. 59-75.

. (coord). 2005. Avaliação do trabalho policial nos registros de ocorrências e nos inquéritos referentes a homicídios dolosos consumados em áreas de delegacias legais. Relatório final de pesquisa. Rio de Janeiro: Instituto de Segurança Pública. Disponível em: http:// urutau. proderj.rj.gov.br/isp_imagens/Uploads/ RelatorioPesquisa003.pdf. Acesso em: 15.set.2011.

. 2008. Informação, análise criminal e sentimento de (in)segurança: considerações para construção de políticas públicas de segurança. In: PINTO, A. S. \& RIBEIRO, L. M. L. 
(orgs.). A análise criminal e o planejamento operacional. de Janeiro: Rio-Segurança.

2010. "Hablar bien" o "hablar mal": reflexiones sobre la Antropología del Estado y de las burocracías. Palestra proferida na mesa redonda "Campos, objetos y sujetos: la Etnografía como modo de construcción de conocimiento", durante as VI de Investigación en Antropología Social, realizado en Buenos Aires.

. No prelo. Resguardar ou punir: produção e usos de registros em Guardas Municipais do Rio de Janeiro. In: SOUZA, L. A. (org.). Avaliação de políticas públicas de segurança. Teoria e prática.

MIRANDA, A. P. M. \& DIRK, R. 2010. Análise da construção de registros estatísticos policiais no Estado do Rio de Janeiro. In: KANT DE LIMA, R.; EILBAUM, L. \& PIRES, L. (orgs.). Conflitos, direitos e moralidades em perspectiva comparada. V. II. Rio de Janeiro: Garamond.

MIRANDA, A. P. M. \& PITA, M. V. 2011. O que as cifras cifram? Reflexões comparativas sobre as políticas de produção de registros estatísticos criminais sobre mortes violentas nas áreas metropolitanas do Rio de Janeiro e de Buenos Aires. In: KANT DE LIMA, R.; PIRES, L. \& EILBAUM, L. (orgs.). Burocracias, direitos e conflitos: pesquisas comparadas em Antropologia do Direito. Rio de Janeiro: Garamond: 175-202.

MIRANDA, A. P. M.; OLIVEIRA, M. B. \& PAES, V. F. 2007. Antropologia e políticas públicas: notas sobre a avaliação do trabalho policial. Cuadernos de Antropología Social, Buenos Aires, v. 25, p. 51-70, ene.-jul. Disponível em: http://www.scielo.org.ar/pdf/cas/ n25/n25a03.pdf. Acesso em: 15.set.2011.

2010. A reinvenção da "cartorializa-ção": análise do trabalho policial em registros de ocorrência e inquéritos policiais em "delegacias legais" referentes a homicídios dolosos na cidade do Rio de Janeiro. Segurança, Justiça e Cidadania, Brasília, ano II, n. 4, p. 119-152.

MISSE, M. 2008. Vitimização e estatísticas policiais na Região Metropolitana do Rio de Janeiro em 2006-2007: uma análise preliminar. In:
PINTO, A. S. \& CAM-PAGNAC, V. (orgs.). Pesquisa de condições de vida e vitimização 2007. Rio de Janeiro: Rio-Segurança.

O'DONNELL, G. 1997 . ¿Y a mí, que mierda me importa? sobre sociabilidad y política en la Argentina y Brasil. In: Contrapuntos. Ensayos escogidos sobre autoritarismo y democratización. Buenos Aires: Paidós.

OLIVEIRA, J. B. P. 2008. Um "raio x" da primeira Delegacia Legal no Estado do Rio de Janeiro: $5^{\text {a }}$ DP (Mem de Sá) em seu primeiro ano de existência. In: MIRANDA, A. P. M. \& LIMA, L. L. G. (orgs.). Politicas públicas de segurança, informação e análise criminal. Niterói: UFF.

OLIVEIRA, R. C. 2000. O trabalho do antropólogo: olhar, ouvir, escrever. In: . O trabalho do antropólogo. Brasília: Paralelo 15.

PAES, V. F. 2006. A Polícia Civil do Estado do Rio de Janeiro: análise de uma (re)forma de governo na Polícia Judiciária. Rio de Janeiro. Dissertação (Mestrado em Sociologia). Universidade Federal do Rio de Janeiro.

PANTALEÓN, J. 2004. Uma nação sob medida. Estatísticas, economia e planificação na Argentina (1918-1952). Rio de Janeiro. Tese (Doutorado em Antropologia Social). Universidade Federal do Rio de Janeiro.

PEIXOTO, G. R. 2008. O Programa Delegacia Legal. Uma história à margem da história. Uma reflexão sobre o propósito e a realidade. In: MIRANDA, A. P. M. \& LIMA, L. L. G. (orgs.). Políticas públicas de segurança, informação e análise criminal. Niterói: UFF.

PERALVA, A. 2000. Violência e democracia: o paradoxo brasileiro. São Paulo: Paz e Terra.

PITA, M. V. 2010. Formas de morir y formas de vivir. activismo contra la violencia policial. Buenos Aires: Del Puerto.

PITA, M. V. \& OLAeTA, H. 2010. Primeiras notas para uma Etnografia da produção de estatísticas oficiais na área criminal. In: KANT DE LIMA, R.; EILBAUM, L. \& PIRES, L. (orgs.). Conflitos, direitos e moralidades em perspectiva comparada. V. II. Rio de Janeiro: Garamond. 
RADCLIFFE-BROWN, A. R. 1970. Preface. In: FORTES, M. \& EVANS-PRITCHARD, E. E. (eds.). African Political Systems. Oxford: Oxford University.
SOUZA, E. G. A. 2008. Feijoada completa: reflexões sobre a administração institucional e dilemas nas Delegacias de Polícia da Cidade do Rio de Janeiro. Niterói. Dissertação (Mestrado em Antropologia). Universidade Federal Fluminense.

\section{OUTRAS FONTES}

BRASIL. 1940. Decreto-Lei n. 2 848, de 7 de dezembro. Código Penal. Diário Oficial, Rio de Janeiro, 31.dez.1940, p. 2391. Disponível em: http:/www.planalto.gov.br/ ccivil_03/decreto-lei/Del2848compilado. htm. Acesso em: 15.set.2011.

DNPC. s/d. Dirección Nacional de Politica Criminal. Buenos Aires.

. 1999a. Manual de instrucciones. Sistema Nacional de Información Criminal y Sistema de Alerta Temprana. Buenos Aires: Dirección Nacional de Política Criminal.

1999b. Instructivo planilla SAT.

Homicidios dolosos. Buenos Aires: Dirección Nacional de Política Criminal.
ISP-RJ. s/d. Dados oficiais. Rio de Janeiro: Instituto de Segurança Pública. Disponível em: http://www.isp.rj.gov.br/Conteudo. asp?ident=150. Acesso em: 15.set.2011.

SESP-RJ. 2003. Programa Delegacia Legal. Manual de delitos e detalhamento de delitos do Sistema de Controle Operacional - SCO. Documento de circulação restrita. Rio de Janeiro: Secretaria Estadual de Segurança do Rio de Janeiro.

2005. Programa Delegacia Legal. Homicídio. Documento de circulação restrita. Rio de Janeiro: Secretaria Estadual de Segurança do Rio de Janeiro. 


\section{BUREAUCRATIC REGIMES AND STATE LANGUAGES: THE POLITICS OF STATISTICAL CRIMINAL RECORDS ON VIOLENT DEATHS IN RIO DE JANEIRO AND BUENOS AIRES}

Ana Paula Mendes de Miranda and María Victoria Pita

This article emerges from our interest in producing a comparable data base for the metropolitan areas of Rio de Janeiro and Buenos Aires. Our research reveals the need to identify the technical processes and political skills that, in Brazil and Argentina, give rise to particular modes of producing information on criminality. This, in turn, requires fleshing out the particular conditions that, in each case, turn official criminal data into the object of political disputes, and lead to intra- and interinstitutional conflicts - as well as turning it into the stuff of "public opinion", as the debate on public safety moves up on the list of public agenda priorities. This approach enables us to conclude that the figures speak more about the institutions that produce them than about criminality or violent deaths in the Rio de Janeiro or Buenos Aires metropolitan regions per se. Therefore, in this article, we try to show that creating comparable data for metropolitan regions as near and as far Buenos Aires and Rio de Janeiro demands its part- by- part examination and disaggregation. Only then can data be compared and read as an indicator of violent forms of conflict resolution.

KEYWORDS: Records; Criminality; Violent Death; Comparison. 


\section{LES ROUTINES BUREAUCRATIQUES ET LES LANGAGES DE L'ETAT : LES POLITIQUES DE REGISTRES STATISTIQUES CRIMINELS SUR LES MORTS VIOLENTES À RIO DE JANEIRO ET À BUENOS AIRES}

\section{Ana Paula Mendes de Miranda et María Victoria Pita}

Cet article part de l'intérêt de produire une base de données comparable des régions métropolitaines de Rio de Janeiro et de Buenos Aires. Tout au long de la recherche, on a vérifié que pour atteindre à cet objectif, il serait nécessaire d'expliciter les processus techniques et les compétences politiques qui ont donné lieu, au Brésil et en Argentine, à des méthodes spécifiques de production d'information en matière de criminalité, en particulier les conjonctures spécifiques qui ont conduit, dans chaque cas, les données officielles sur la criminalité à devenir l'objet de disputes politiques, et à l'existence de conflits intra et inter-institutionnels. Ce qui était aussi, un sujet dont «l'opinion publique » s'en nourrissait, au moment où le débat sur la sécurité publique s'élevait dans le classement de l'agenda public. Cette approche nous permet de conclure que les chiffres parlent plus sur les institutions que l'ont produite, au lieu de parler sur la criminalité ou sur la situation des morts violentes dans les régions métropolitaines de Rio de Janeiro et de Buenos Aires. Donc, cet article présentera la façon dont ces données ont dû être (dé) composées et (dés) agrégées pour être comparées et lues autant qu'indicateurs de formes violentes de résolution de conflits, pour qu'elles puissent enfin être considérées comparables entre des régions métropolitaines aussi proches et aussi distantes comme Buenos Aires et Rio de Janeiro.

MOTS-CLÉS: les registres ; la criminalité ; les morts violentes ; la comparaison. 